\title{
2015 CIPHI award winners
}

The 2015 CIPHI Awards were handed out during the most recent National AGM in September in Ottawa. Congratulations to all the winners!

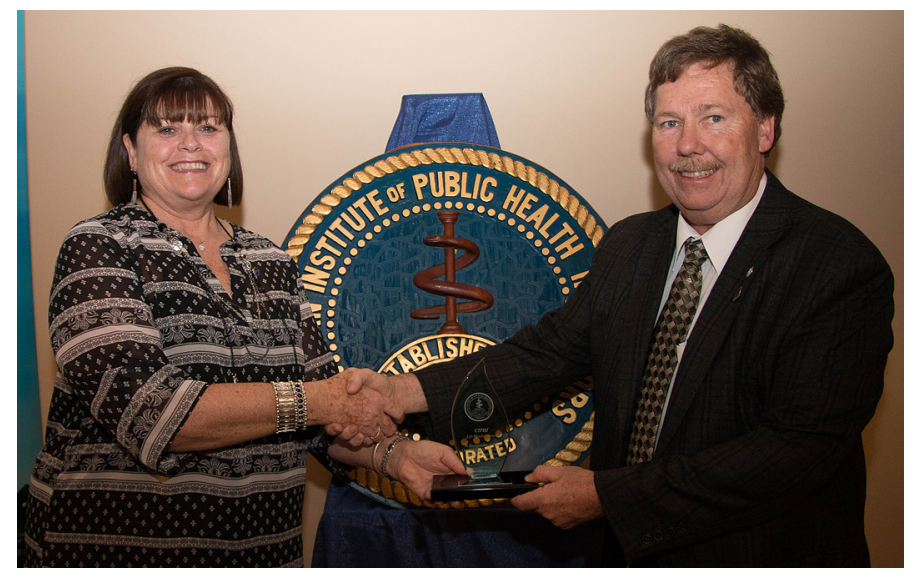

Pamela Scarfe, Ontario Member (left), receiving the 2015 Life Member Award from Ralph Stanley (right).

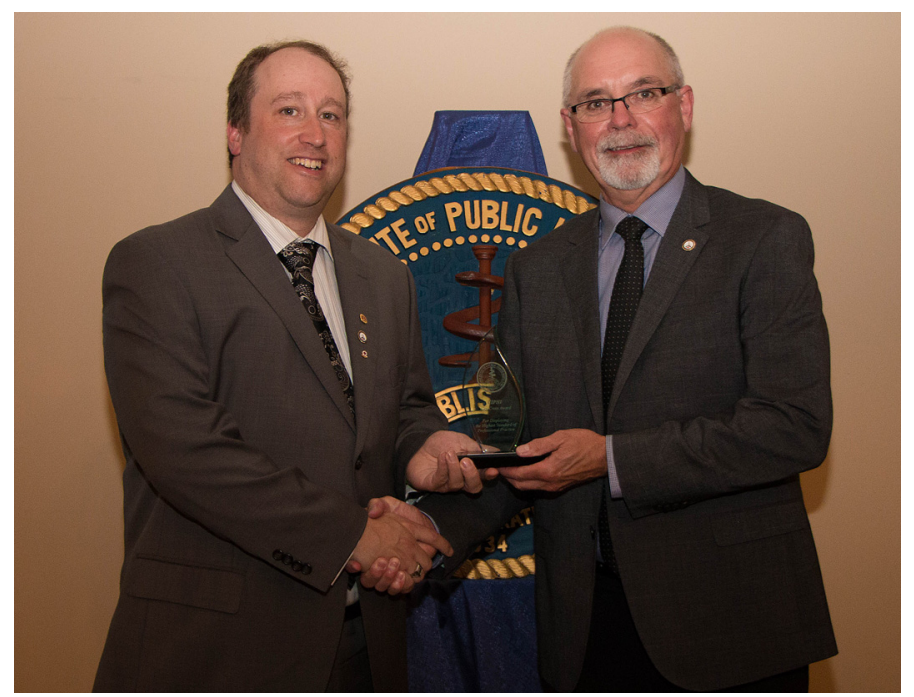

Sean O'Toole, NEC Award Committee Co-Chair and NS/PEI President (left) presenting the 2015 Alex Cross Award to Joe Bradley, NS/PEI Branch Member (right).

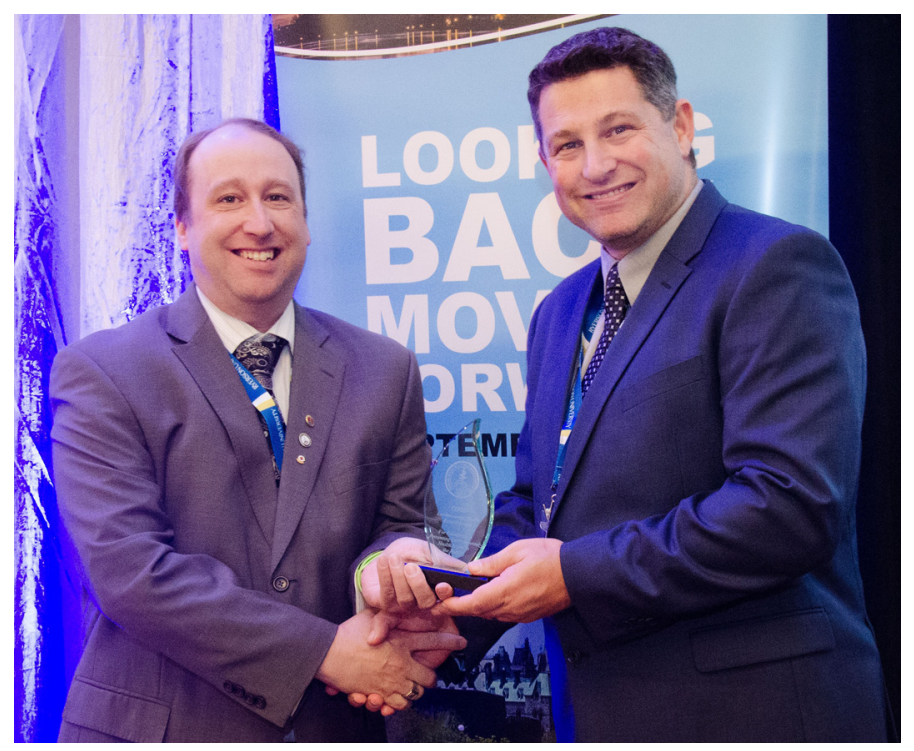

Sean O'Toole, NEC Award Committee Co-Chair and NS/PEI President (left) presents the 2015 Environmental Health Review Award to Cameron Weighill, Past ON President (right), who is accepting on behalf of the Central East Tobacco Control Network. 


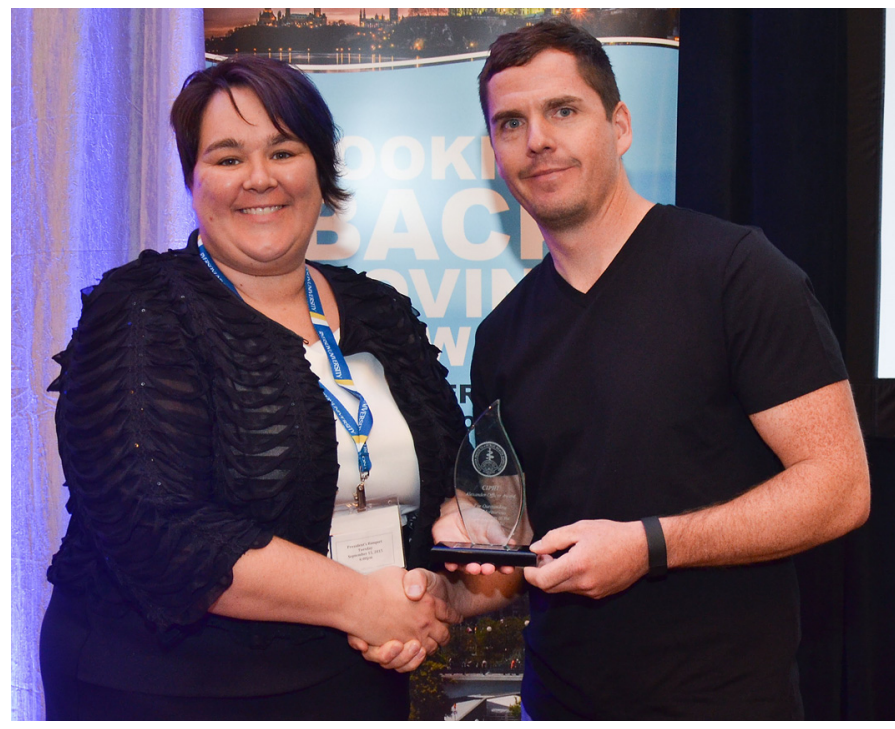

Kari Engle-Carter, NEC Award Committee Co-chair and SK President (left) with Jason MacDonald, AB Branch President, who is accepting the 2015 Alexander Officer Award on behalf of the Alberta Health Services- Environmental Public Health Team (Person with Disabilities).

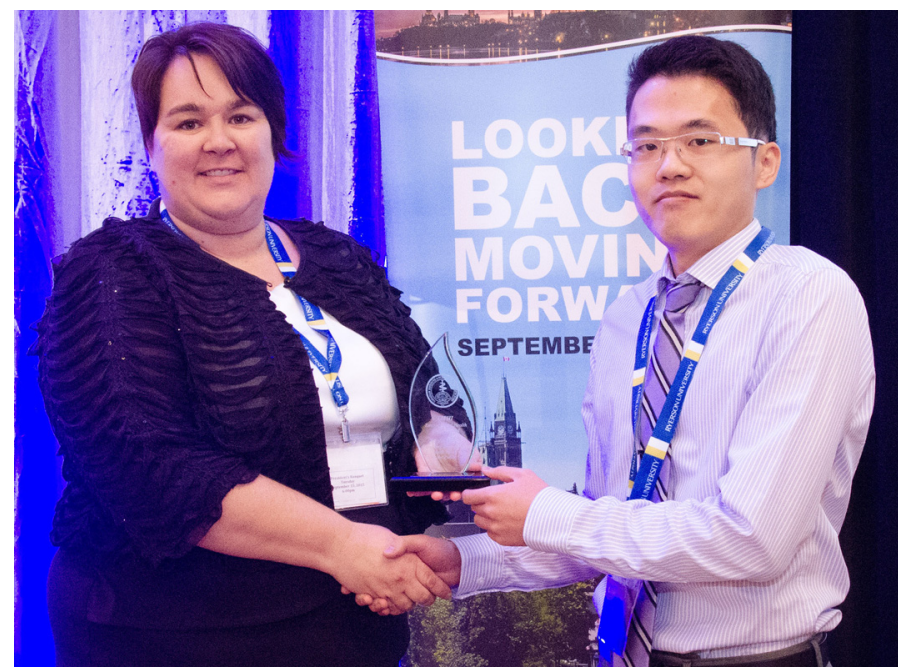

Kari Engle-Carter, NEC Award Committee Co-chair and SK President (left) with Thomas Cheung, AB Member (right), accepting the 2015 Environmental Health Review Award on behalf of the Technical Advisory Panel for Personal Services.

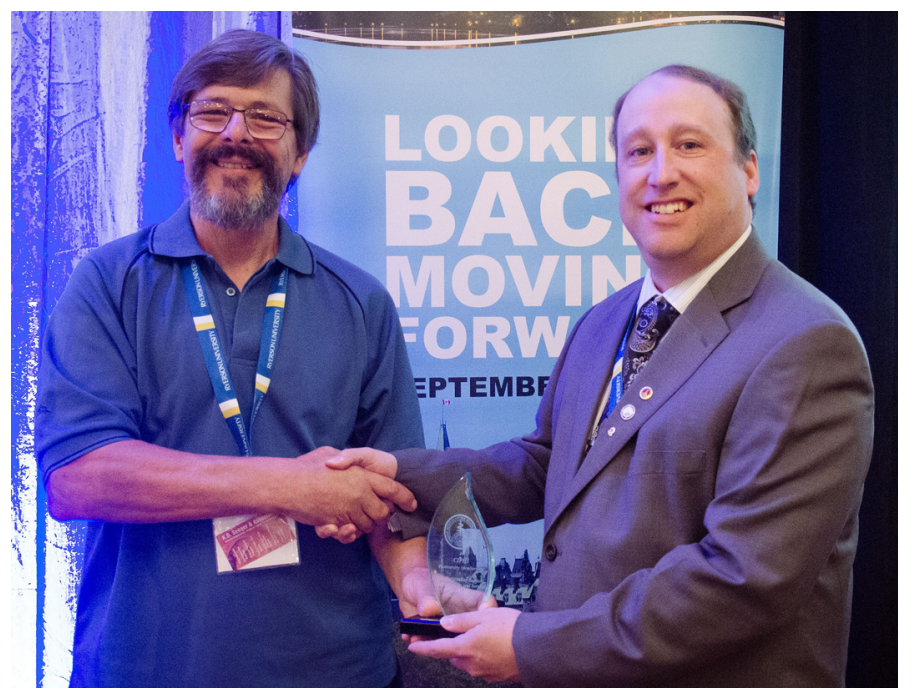

Klaus Seeger accepting the 2015 Honorary Member Award on behalf of his wife Rhea Hamilton Seeger (left), presented by Sean O'Toole, NEC Award Committee Co-Chair and NS/ PEI President (right).

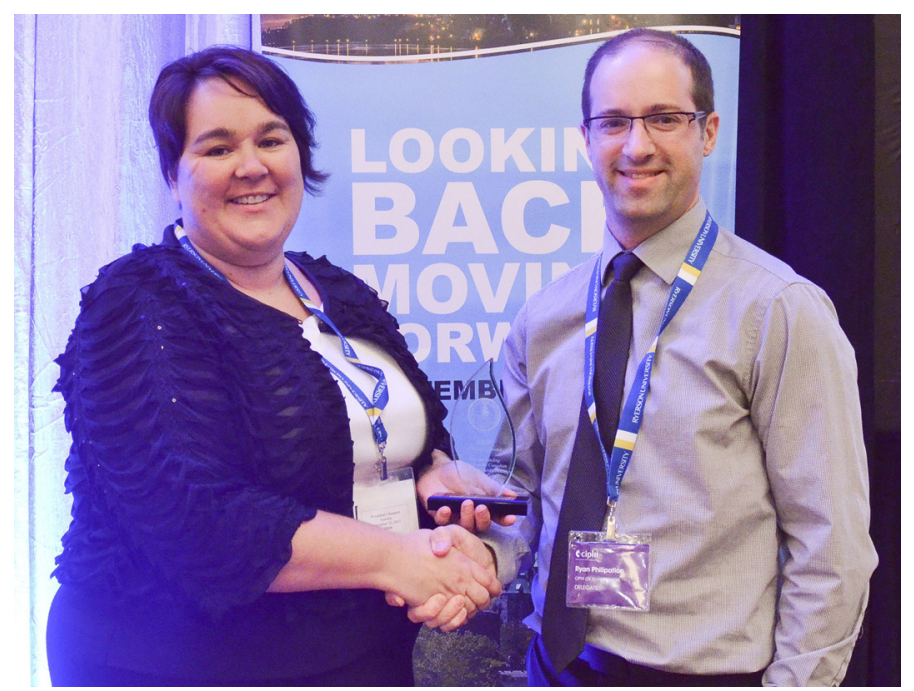

Kari Engle-Carter, NEC Award Committee Co-chair and SK President (left), with Ryan Phillipation, SK Member and Past SK President who is the 2015 Presidents Award recipient. 